\title{
Avaliação da Intoxicação de Cultivares de Cana-De-Açúcar e I. grandifolia AO AMICARBAZONE ${ }^{1}$
}

\author{
Evaluation of Intoxication of Sugarcane Cultivars and I. grandifolia by Amicarbazone
}

\author{
ARALDI, R. ${ }^{2}$, VELINI, E.D. ${ }^{3}$, GIROTTO, M. ${ }^{2}$, CARBONARI, C.A. ${ }^{4}$, GOMES, G.L.G.C. ${ }^{2}$ e \\ TRINDADE, M.L.B. ${ }^{4}$
}

\begin{abstract}
RESUMO - O objetivo deste trabalho foi avaliar a intoxicação de planta daninha e cultivares de cana-de-açúcar ao amicarbazone. Para isso, utilizou-se Ipomoea grandifolia como planta daninha representante e os cultivares de cana-de-açúcar PO8862, SP80 3280 e RB83 5486, caracterizados como sensivel, intermediário e tolerante aos herbicidas, respectivamente. Foi verificado o consumo de água e quantificada a concentração do amicarbazone em seiva de xilema dos três cultivares de cana-de-açúcar e de I. grandifolia por meio da bomba de Schollander e da cromatografia e espectrometria de massas (LC-MS). A intoxicação das plantas foi verificada através de leituras da fluorescência, com auxilio do fluorômetro portátil, que permitiu a correlação da taxa de transporte de elétrons (ETR) com a concentração de amicarbazone absorvido pelos cultivares de cana-de-açúcar e por I. grandifolia. Verificou-se, através do experimento, que a redução dos valores da ETR pode ser utilizada para indicar o nivel de intoxicação de I. grandifolia e de plantas de cana-de-açúcar ao amicarbazone. I. grandifolia destacou-se em relação à cana-de-açúcar pela maior sensibilidade ao amicarbazone. A suscetibilidade diferencial dos cultivares de cana-de-açúcar PO8862, SP80 3280 e RB83 5486 pode ser justificada, possivelmente, pela absorção diferencial do amicarbazone entre os cultivares.
\end{abstract}

Palavras-chave: seletividade, fotossíntese, fluorescência, fluorômetro.

\begin{abstract}
The objective of this work was to evaluate the intoxication of weeds and sugarcane cultivars by amicarbazone. Ipomoea grandifolia was used as weed representative and the sugarcane cultivars PO8862, SP80 3280, and RB835486, characterized as sensitive, intermediate and tolerant to herbicides, respectively. Water consumption was verified and amicarbazone concentration quantified in the xylem sap of the three sugarcane cultivars and of I. grandifolia, using the Schollander pump and chromatography and mass spectrometry (LC-MS). Plant intoxication was verified by fluorescence readings with the aid of portable fluorometer, which allowed the correlation of the electron transport rate (ETR) with the concentration of amicarbazone absorbed by the sugarcane cultivars and I. grandifolia. Thus, it could be verified through experiments that the reduction of ETR values may be used to indicate the level of intoxication of I. grandifolia, and sugarcane plants by amicarbazone. I. grandifolia was more sensitive to amicarbazone than sugarcane. The differential susceptibility of the sugarcane varieties PO8862, SP80 3280, and RB83 5486 can be justified possibly by the differential absorption of amicarbazone among cultivars.
\end{abstract}

Keywords: selectivity, photosynthesis, fluorescence, fluorometer.

Recebido para publicação em 1ํ.12.2010 e aprovado em 17.2.2011.

2 Pós-Graduação em Agronomia pela Faculdade de Ciências Agronômicas, Universidade Estadual Paulista Júlio de Mesquita Filho - FCA/UNESP, Campus de Botucatu, Fazenda Experimental Lageado, Caixa Postal 237, 18603-970 Botucatu-SP, $<$ araldi@fca. unesp.br>; ${ }^{3}$ Professor, Dr., Dep. de Agricultura, FCA/UNESP, ${ }^{4}$ Doutores, FCA/UNESP, Núcleo de Pesquisa Avançada em Matologia - NUPAM.

Planta Daninha, Viçosa-MG, v. 29, n. 4, p. 869-875, 2011 


\section{INTRODUÇÃO}

Para controlar as plantas daninhas e evitar os possiveis prejuízos à cultura da cana-deaçúcar, muitos herbicidas com diferentes ingredientes ativos e formulações estão registrados para uso no Brasil. Dos herbicidas registrados para cana-de-açúcar, o amicarbazone é um dos mais importantes para o controle das plantas daninhas (Toledo et al., 2004). Para que ocorra o efetivo controle das plantas daninhas com a aplicação de herbicidas, é preciso que o herbicida aplicado, além de ser absorvido, translocado e redistribuído pelas plantas, chegue até o sítio de ação em quantidade suficiente para ser fitotóxico, ou seja, uma vez presente na célula, interfira nos processos vitais específicos da planta. Como o amicarbazone é um herbicida inibidor da fotossintese, torna-se necessário que ele alcance os cloroplastos das células das folhas para atuar em seu sítio de ligação no fotossistema II.

O herbicida amicarbazone como inibidor da fotossintese liga-se à proteína $\mathrm{D}_{1}$, não permitindo a transferência de elétrons entre as $\mathrm{Q}_{\mathrm{A}}$ e $\mathrm{Q}_{\mathrm{B}}$ no fotossistema II. Uma vez ligado o herbicida à proteína e estando a planta submetida a elevadas taxas de radiação fotossinteticamente ativa, ocorre a formação de radicais livres, os quais promovem a peroxidação de membranas, além do aumento da emissão de fluorescência pelo aparato fotossintético (Yamamoto, 2001).

A emissão de fluorescência fornece informações sobre os processos fotoquímicos do PSII em plantas. Sob condição de baixa luz, em torno de $95 \%$ dos fótons absorvidos são usados na fase fotoquímica, 4,5\% são transformados em calor e $0,5 \%$ é reemitido como luz fluorescente. Se todos os centros de reação do PSII estiveram fechados por um bloqueio da fotossintese, $95-97 \%$ da energia pode ser dissipada como calor e 2,5-5,0\% dissipada via fluorescência (Bolhàr-Nordenkampf \& Oquist, 1993).

A análise cinética da fluorescência oferece muitas vantagens como instrumento qualitativo para o estudo do transporte de elétrons durante a fotossintese, visto que o processo de obtenção de medidas da fluorescência da clorofila é rápido, específico e não destrutivo (Mohanty \& Govindjee, 1974). Com um fluorômetro, é possivel registrar o comportamento da fase inicial da fotossintese, que é o transporte de elétrons no PSII, sendo este o sítio de ação do amicarbazone.

Van Oorschot \& van Leeuwen (1992) conduziram experimento com folhas destacadas de Alopecurus myosuroides suscetiveis e resistentes ao chlortoluron. As folhas das plantas resistentes mostraram parcial a completa recuperação da inibição do transporte de elétrons, enquanto as plantas suscetiveis não mostraram qualquer recuperação do transporte de elétrons no PSII.

Em trabalho desenvolvido por Dayan et al. (2009), foi monitorada a taxa de transporte de elétron do fotossistema II (ETR) em plantas de milho, Digitaria sanguinalis e Abutilon theophrasti, quando submetidas à aplicação de amicarbazone e atrazine. A taxa de transporte de elétrons para Digitaria sanguinalis e Abutilon theophrasti foi completamente inibida oito horas após a aplicação do herbicida, enquanto o milho manteve redução de aproximadamente 70 e $30 \%$ do ETR fotossintético com 24 horas após a aplicação do amicarbazone e atrazine, respectivamente; o milho foi mais tolerante aos herbicidas testados, quando comparado às plantas daninhas.

Para o sucesso no controle químico das plantas daninhas na produção da canade-açúcar é importante a seletividade de herbicidas na cultura. Alguns cultivares apresentam respostas diferenciadas aos herbicidas, tendo como consequência frequentes problemas de fitotoxicidade, chegando a ocasionar redução na produtividade do canavial para os cultivares mais sensiveis. Essa intoxicação, dependendo do genótipo e das características do herbicida utilizado, além de afetar a fotossintese em sua fase inicial (transporte de elétrons no PSII), pode alterar a produtividade e a qualidade da matéria-prima da cana-de-açúcar (Velini et al., 2000).

Korres et al. (2003) investigaram a influência do chlortoluron em dois cultivares de trigo que se destacavam por exibir diferença na resposta ao herbicida. Com a detecção da fluorescência do PSII, foi possivel verificar a resposta diferencial do herbicida entre os cultivares de trigo. Yordanova et al. (2001) mostraram também que plantas de tabaco não 
transgênicas (suscetíveis ao chlortoluron) apresentaram maior inibição do transporte de elétrons em relação às plantas transgênicas - plantas estas que se destacavam pela tolerância ao chlortoluron.

O objetivo deste trabalho foi avaliar a intoxicação de $I$. grandifolia e três cultivares de cana-de-açúcar ao amicarbazone.

\section{MATERIAL E MÉTODOS}

No experimento foi utilizada a espécie I. grandifolia como planta daninha e os cultivares de cana-de-açúcar PO8862, SP80 3280 e RB83 5486, classificados como sensivel, intermediário e tolerante aos herbicidas, respectivamente.

As plantas foram cultivadas em substrato por cerca de 30 dias, após o que foram coletadas e tiveram suas raízes lavadas para remoção do substrato do sistema radicular. $\mathrm{O}$ sistema radicular das plantas foi imerso em soluções contendo duas concentrações de amicarbazone. Essas concentrações foram selecionadas a partir dos resultados de estudos de campo anteriores, em que se coletaram e determinaram as concentrações do amicarbazone em solução do solo.

$\mathrm{O}$ experimento foi instalado em delineamento inteiramente casualizado, com cinco repetições, e os tratamentos consistiram de diferentes concentrações de amicarbazone. A primeira concentração foi de $0,250 \mathrm{mg} \mathrm{L}^{-1}$ de amicarbazone na solução, correspondente à quantidade de herbicida encontrada no solo com aplicação normal. A segunda aplicação foi com o dobro da dose recomendada $\left(0,500 \mathrm{mg} \mathrm{L}^{-1}\right)$ de amicarbazone. Foram mantidas plantas em água como testemunha. As plantas foram mantidas em condições controladas em câmara climatizada, com temperatura de 25 a $30{ }^{\circ} \mathrm{C}$ e umidade relativa de $60 \%$.

Nos períodos de 2, 6, 24, 48, 48, 96 e 144 horas após o contato das plantas com o amicarbazone, foi avaliada, na porção mediana das folhas de cana-de-açúcar e da planta daninha, a leitura da taxa de transporte de elétrons (ETR), com um fluorômetro portátil. Com o fluorômetro é possivel registrar o comportamento da fase inicial da fotossintese, que é o transporte de elétrons no PSII, sendo este o sítio de ação do amicarbazone. A fonte de luz utilizada para medir a fluorescência no aparelho Multi-Mode Chlorophyll Fluorometer OS5p (Opti-Sciences) foi a fonte diodo com pico de luz vermelha no comprimento de onda de $660 \mathrm{~nm}$, sendo bloqueadas radiações maiores que $690 \mathrm{~nm}$. A intensidade média da luz foi ajustada para o intervalo de 0 a $1 \mu \mathrm{Mol} \cdot \mathrm{m}^{-2} \cdot \mathrm{s}^{-1}$, com o uso da lâmpada halogênica $35 \mathrm{~W}$. O feixe de luz é opticamente monitorado no interior da câmara, para corrigir as variações decorrentes de mudanças na temperatura do ambiente. Os sinais ópticos são transferidos para a superfície da folha por uma trifurcação personalizada de fibra óptica, sendo de $2 \mathrm{~cm}^{2}$ a área iluminada. A luz reemitida é conduzida via fibra óptica para o aparelho por meio de três conectores, que são ligados na lateral do OS5p. As análises foram feitas seguindo a metodologia de Genty et al. (1989), avaliando a emissão da fluorescência da clorofila na superficie superior das folhas.

No que se refere a iluminação e detecção da fluorescência da clorofila das amostras de cana-de-açúcar e planta daninha, foi utilizado o protocolo Yield para mensuração da taxa de transporte de elétrons. Esse protocolo é otimizado para um estado da fotossintese adaptado à luz porque registra as medidas de quantum efetivo produzido no PSII. Tanto a fonte de luz do sol quanto a luz artificial podem ser usadas para dirigir a fotossintese.

Taxa de transporte de elétrons (ETR) $\mu$ Mols elétrons $\mathrm{m}^{-2} \mathbf{s}^{-1}=(\mathrm{Y}) \cdot(\mathrm{PAR}) \cdot(0,84) \cdot(0,5)$ é equivalente a: (produção de quantum do PSII) $\mathrm{x}$ (medidas da radiação fotossinteticamente ativa em $\mu$ Mols elétrons $\mathrm{m}^{-2} \mathrm{~s}^{-1}$ ) $\mathrm{x}$ (coeficiente de absorção da folha) x (fração de luz absorvida pelo complexo antena do PSII). O ETR é uma medida da separação de cargas do centro de reação do PSII. Na equação são usados valorespadrão, porém ambos os coeficientes de absorção e fração da luz absorvida pelo PSII podem ser trocados. Embora 0,84 seja um valor médio para muitas espécies de plantas, trabalhos têm mostrado que o coeficiente de absorção da folha pode variar com a qualidade da luz, a espécie, o conteúdo de clorofila e a refletância da folha. Para a fração de luz que é absorvida pelo complexo antena do PSII, os trabalhos mostram que ocorre variação de acordo com a espécie, ficando entre de 0,42 e 0,60 (Laisk \& Loreto, 1996). 
Como o parâmetro ETR determina a taxa de transporte de elétrons fotossintéticos no PSII, o uso do valor do ETR permite detectar o efeito da atuação do herbicida em nivel de concentração de 0,5 micromoles $\mathrm{dm}^{-3}$, enquanto o método tradicional, que inclui a medição do parâmetro $\mathrm{Fv} / \mathrm{Fm}$, permite detectar apenas em um nível de concentração que é 100 vezes maior (Korres et al., 2003; Abbaspor et al., 2006).

Os dados de ETR foram associados às informações sobre consumo de água, verificado diariamente através da pesagem, e também com os dados de absorção do amicarbazone, obtidos pela metodologia de extração de seiva com a bomba de Schollander e de quantificação do composto com a cromatografia e espectrometria de massas (LC-MS).

$\mathrm{O}$ amicarbazone absorvido pelo sistema radicular foi calculado através da multiplicação do consumo de água acumulado das plantas pela concentração de herbicida em solução e, na sequência, pela concentração de herbicida detectado na seiva das plantas. Dividindo esses valores pela área foliar de cada planta, foi possivel estimar o acúmulo de herbicida absorvido pelo sistema radicular em cada intervalo, em função da área foliar.

As regressões geradas das correlações foram analisadas com o programa Sigma Plot, versão 11, com uso das seguintes equações/ funções.

A equação linear com a reta passando pelo valor 100 em y, utilizada para ajustar os dados de ETR em relação ao amicarbazone absorvido dos cultivares de cana-de-açúcar PO8862 e RB83 5486, foi:

$$
y=100-(b x)
$$

em que $y$ representa o valor da taxa de transporte de elétrons (ETR); $b$ é o coeficiente de inclinação da reta; e $x$, a concentração do amicarbazone absorvido.

A equação logística utilizada para ajustar os dados de ETR, em relação ao amicarbazone absorvido do cultivar de cana-de-açúcar SP80 3280, foi:

$$
y=c+\frac{d-c}{1+\left(x / V_{50}\right)^{b}}
$$

Planta Daninha, Viçosa-MG, v. 29, n. 4, p. 869-875, 2011 em que $y$ representa o ETR; $x$ representa a concentração do herbicida; $d$ denota o limite máximo e $c$ o limite mínimo; $V_{50}$ denota a dose requerida para metade da resposta de $y$ entre $d$ e $c$; e o parâmetro $b$ refere-se à eficiência da dosagem utilizada.

A equação hiperbólica racional, para ajustar os dados de ETR em relação ao amicarbazone absorvido para I. grandifolia, foi assim descrita:

$$
y=\frac{1}{a+(b x)}
$$

em que $y$ representa o ETR; $x$ representa a concentração do herbicida; o coeficiente $a$ denota interseção; e o coeficiente $b$, inclinação da reta.

\section{RESULTADOS E DISCUSSÃO}

Nas Figuras de 1 a 4 encontram-se os dados de ETR em relação à quantidade de amicarbazone absorvido para os cultivares de canade-açúcar PO8862, SP80 3280 e RB83 5486 e para a espécie $I$. grandifolia, respectivamente. Na Figura 5, pode-se observar um comparativo entre as respostas de todas as plantas estudadas.

A análise de mudanças na fluorescência da clorofila, detectada, pelo fluorômetro, oferece muitas possibilidades não só para determinar a inibição do transporte de elétrons pelo herbicida, mas também para relacionar essas injúrias com a taxa de absorção do herbicida e/ou concentração aplicada (Richard Jr et al., 1983).

Com a inibição do ETR, nas plantas ocorre o comprometimento da taxa de assimilação de carbono pela não formação de ATP e NADPH nos cloroplastos das plantas. Ao final, com a diminuição da fotossintese líquida induzida pela ação de herbicida, o balanço de carbono da folha tende a ser cada vez menos positivo, até o esgotamento da planta.

A planta daninha $I$. grandifolia foi mais sensivel em relação aos cultivares de canade-açúcar quando submetida ao amicarbazone em solução. Uma quantidade de apenas $0,0029 \mathrm{nMol} \mathrm{cm}^{-2}$ de amicarbazone foi suficiente para inibição de $50 \%$ do ETR da planta daninha (Figura 4). Para a cana-deaçúcar, esses valores para inibição de $50 \%$ do 
ETR foram maiores, sendo de 0,0310, 0,0430

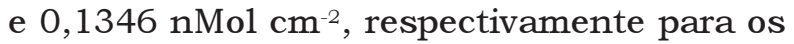

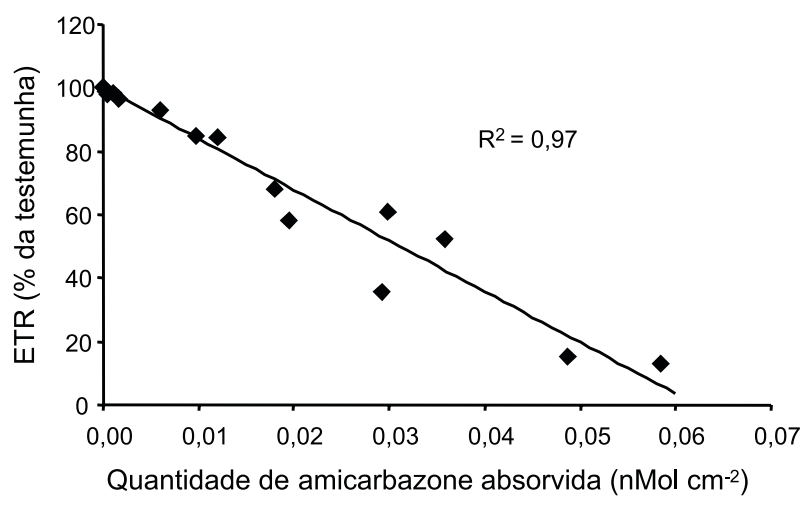

Figura 1 - Comportamento da taxa de transporte de elétrons (ETR) da fotossíntese do cultivar de cana-de-açúcar PO8862, em relação à quantidade de amicarbazone absorvida pelas plantas. Os dados foram ajustados com o uso da equação linear. Botucatu-SP, 2010.

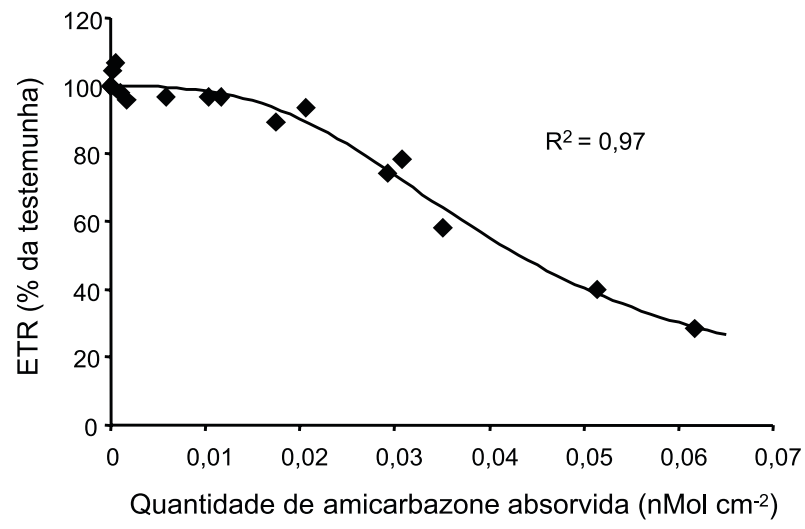

Figura 2 - Comportamento da taxa de transporte de elétrons (ETR) da fotossíntese do cultivar de cana-de-açúcar SP80 3280 em relação à quantidade de amicarbazone absorvida pelas plantas. Os dados foram ajustados com o uso do modelo logístico. Botucatu-SP, 2010. cultivares PO8862, SP80 3280 e RB83 5486

(Figuras 1, 2 e 3).

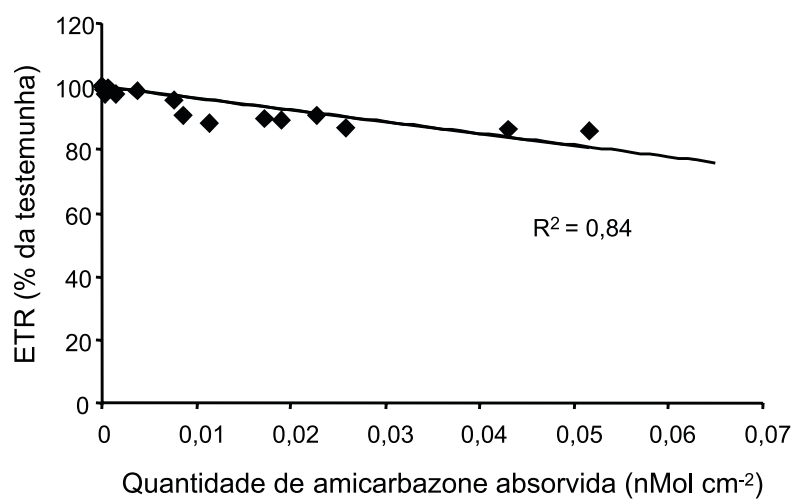

Figura 3 - Comportamento da taxa de transporte de elétrons (ETR) da fotossíntese do cultivar de cana-de-açúcar RB83 5486, em relação à quantidade de amicarbazone absorvida pelas plantas. Os dados foram ajustados com o uso da equação linear. Botucatu-SP, 2010.

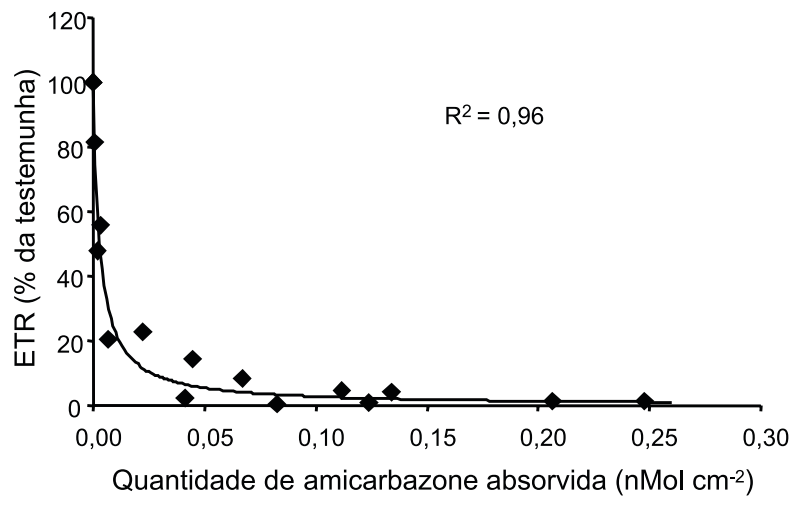

Figura 4 - Comportamento da taxa de transporte de elétrons (ETR) da fotossíntese da planta daninha I. grandifolia, em relação à quantidade de amicarbazone absorvida pelas plantas. Os dados foram ajustados com o uso do modelo hiperbólico racional. Botucatu-SP, 2010.

Tabela 1 - Consumo de água, concentração de amicarbazone em seiva de xilema e índice combinado entre consumo de água e concentração de herbicida em seiva para a planta daninha I. grandifolia e para os cultivares de cana-de-açúcar PO8862, SP80 3280 e RB83 5486. Botucatu-SP, 2010

\begin{tabular}{|l|c|c|c|}
\hline \multicolumn{1}{|c|}{ Espécie } & $\begin{array}{c}\text { Consumo de água } \\
\left(\mathrm{cm}^{3} \mathrm{~cm}^{-2}\right)\end{array}$ & $\begin{array}{c}\text { Concentração herbicida } \\
\text { em seiva } \\
(\%)^{*}\end{array}$ & Índice combinado \\
\hline Ipomoea grandifolia & 0,2576 & 53,86 & 13,86 \\
\hline Cana-de-açúcar (PO8862) & 0,1623 & 5,22 & 0,85 \\
\hline Cana-de-açúcar (SP80 3280) & 0,1287 & 6,13 & 0,79 \\
\hline Cana-de-açúcar (RB83 5486) & 0,1152 & 4,70 & 0,54 \\
\hline
\end{tabular}

* Relação em porcentagem entre as concentrações de herbicidas na seiva de xilema e na solução fornecida ao sistema radicular para as plantas. 
Dayan et al. (2009), trabalhando com milho, Digitaria sanguinalis e Abutilon theophrasti, correlacionaram o comportamento do ETR com a quantidade de amicarbazone interceptada pelas plantas e verificaram que os ETRs de Digitaria sanguinalis e Abuthilon theophrasti foram mais afetados em relação ao milho.

Essa resposta diferenciada do ETR em relação ao amicarbazone absorvido, em $\mathrm{nMol} \mathrm{cm}{ }^{2}$, possivelmente esteja relacionada com a absorção do herbicida pelas plantas. De acordo com o indice combinado entre os valores de consumo de água e concentração de amicarbazone na seiva do xilema (Tabela 1 ), tem-se 13,86 para I. grandifolia e 0,85, 0,79 e 0,54 para os cultivares de cana-de-açúcar PO8862, SP80 3280 e RB83 5486, respectivamente, demonstrando que $I$. grandifolia mostrou maior sensibilidade ao herbicida. Negrisoli et al. (2007), trabalhando com a aplicação de amicarbazone em plantas daninhas, constataram alta eficácia do herbicida para I. grandifolia.

A diferença no comportamento da relação ETR (Figura 5) para os cultivares de cana-deaçúcar é justificada pela quantidade de amicarbazone absorvida, visto que no caso do cultivar sensível (PO8862) ocorreu maior absorção do herbicida e, consequentemente, saturação dos processos de desintoxicação das

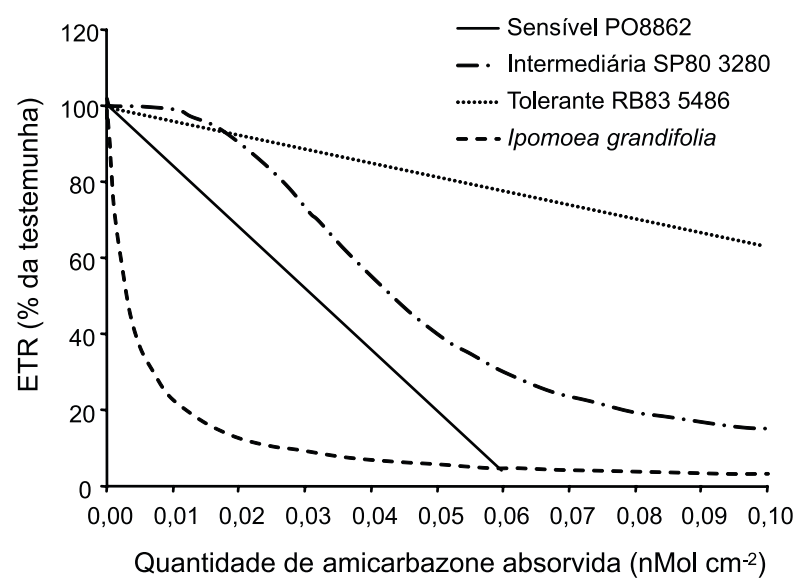

Figura 5 - Comportamento da taxa de transporte de elétrons (ETR) da fotossíntese para os cultivares de cana-de-açúcar PO8862, SP80 3280 e RB83 5486 e para a planta daninha I. grandifolia, em relação à quantidade de amicarbazone absorvida pelas plantas. Botucatu-SP, 2010. plantas. Esses dados podem ser correlacionados, já que entre os cultivares de cana-deaçúcar verificou-se maior absorção do amicarbazone para o cultivar sensivel PO8862 e menor para o cultivar tolerante RB83 5486, com 36\% de diferença entre ambos - avaliada pelo índice combinado de consumo de água e concentração de amicarbazone em seiva de xilema. O cultivar SP80 3280 manteve comportamento intermediário quanto à absorção do amicarbazone em solução.

A classificação de sensibilidade ao amicarbazone entre os cultivares de cana-deaçúcar foi feita de acordo com as respostas observadas, na sequência: PO8862, SP80 3280 e RB83 5486, da maior para a menor sensibilidade, respectivamente. Ferreira et al. (2005), ao trabalharem com 15 genótipos de cana-deaçúcar, verificaram que os cultivares apresentaram também sensibilidade diferencial à mistura de ametryn+trifloxysulfuron-sodium: o cultivar RB85 5113 demonstrou alta sensibilidade, ao passo que os cultivares SP80 1842, SP79 1011 e RB95 7689 mostraram média sensibilidade à mistura de herbicidas.

Souza et al. (2009) buscaram avaliar a tolerância de cultivares de cana-de-açúcar a herbicidas aplicados em pós-emergência na soqueira da cultura. Foi detectada pequena redução no transporte de elétrons do PSII na fase inicial de desenvolvimento da cultura, porém não foi suficiente para prejudicar a altura, o estande, a produção e a qualidade tecnológica dos diferentes cultivares de canade-açúcar estudados. Analisando a diferença na sensibilidade de materiais de aveia submetidos ao herbicida chlortoluron, Skórska \& Murkowski (2009) verificaram que plantas de aveia-selvagem (Avenua fatua) sofreram considerável diminuição do transporte de elétrons nas folhas (26\% do valor de ETR) quando comparadas com a testemunha, enquanto não ocorreu mudança na capacidade de transporte de elétrons no PSII para a aveia cultivada (Avenua sativa). Comportamento semelhante foi observado no trabalho de aplicação do amicarbazone nos cultivares de cana-de-açúcar sensivel e tolerante aos herbicidas.

Korres et al. (2003) investigaram a influência do chlortoluron em dois cultivares de trigo que se destacavam por exibir diferença na resposta ao herbicida. Com a detecção 
da fluorescência do PSII, foi possível verificar a resposta diferencial do herbicida entre os cultivares de trigo. Yordanova et al. (2001) mostraram também que plantas de tabaco não transgênicas (suscetível ao chlortoluron) apresentaram maior inibição do transporte de elétrons em relação às transgênicas - plantas estas que se destacavam pela tolerância ao chlortoluron.

De maneira geral, a redução dos valores da ETR pode ser utilizada para indicar o nivel de intoxicação de plantas daninhas e de plantas de cana-de-açúcar ao amicarbazone um potente inibidor do PSII. I. grandifolia destacou-se em relação à cana-de-açúcar pela maior sensibilidade ao amicarbazone. A suscetibilidade diferencial dos cultivares de cana-de-açúcar PO8862, SP80 3280 e RB83 5486 pode ser justificada, possivelmente, pela absorção diferencial do amicarbazone entre os cultivares.

\section{LITERATURA CITADA}

ABBASPOOR, M.; TEICHER H. B.; STREIBIG, J.C. The effect of root-absorbed PSI inhibitors on Kautsky curve parameters in sugar beet. Weed Res., v. 46, n. 3, p. 226-235, 2006.

BÒLHAR-NODENKAMPF, H. R.; OQUIST, G. O. Chlorophyll fluorescence as a tool in photosynthesis research. In: HALL, D. O. et al. (Eds.). Photosynthesis and production in a changing environment. London: Chapman \& Hall, 1993. p. 193-206.

DAYAN, F. E.; TRINDADE, M. L. B.; VELINI, E. D. Amicarbazone, a new photosystem II inhibitor. Weed Sci., v. 57, p. $579-583,2009$

FERREIRA, E. A. et al. Sensibilidade de cultivares de canade-açúcar à mistura trifloxysulfuron-sodium+ametryn.

Planta Daninha, v. 23, n. 1, p. 93-99, 2005.

GENTY, B.; BRIANTAIS, J. M.; BAKER, N. R. The relationship between the quantum yield of photosynthetic electron-transport and quenching of chlorophyll fluorescence. Biochim.t Biophys Acta, v. 990, n. 1, p. 87-92, 1989.

KORRES, N. E.; FROUD-WILLIAMS, R. J.; MOSS, S. R. Chlorophyll fluorescence technique as a rapid diagnostic test of the effects of the photosynthetic inhibitor chlortoluron on two winter wheat cultivars. Ann. Appl. Biol., v. 143, n. 1, p. $53-56,2003$
LAISK, A.; LORETO, F. Determining photosynthetic parameters from leaf $\mathrm{CO}_{2}$ exchange and chlorophyll fluorescence. Ribulose-1,5-bisphosphate carboxylase/ oxygenase specificity factor, dark respiration in the light, excitation distribution between photosystems, alternative electron transport rate, and mesophyll diffusion resistance. Plant Physiol., v. 110, n. 3, p. 903-912, 1996.

MOHANTY, P.; GOVINDJEE, G. The slow decline and the subsequent rise of chlorophyll fluorescence transients in intact algal cells. Plant Biochem. J., v. 1, n. 1, p. 78-106, 1974.

NEGRISOLI, E. et al. Controle de plantas daninhas pelo amicarbazone aplicado na presença de palha de canade-açúcar. Planta Daninha, v. 25, n. 3, p. 603-611, 2007.

Van OORSCHOT, J. L. P.; van LEEUWEN, P. H. Use of fluorescence induction to diagnose resistance of Alopecurus myosuroides Huds. (black-grass) to chlorotoluron. Weed Res., v. 32, n. 5, p. 473-482, 1992.

RICHARD JR., E. et al. Determination of herbicide inhibition of photosynthetic electron transport by fluorescence. Weed Sci., v. 31, n. 3, p. 361-367, 1983.

SKÓRSKA, E.; MURKOWSKI, A. Comparison of susceptibility of crop oat cv.AKT and wild oat leaves to Dicuran $80 \mathrm{WP}$ in mixture with two adjuvants, measured by chlorophyll fluorescence. Acta Agrophys, v. 14, n. 2 , p. 463-468, 2009.

SOUZA, J. R. et al. Tolerância de cultivares de cana-de-açúcar a herbicidas aplicados em pós-emergência. Bragantia, v. 68, n. 14, p. 873-884, 2009.

TOLEDO, R. E. B. et al. Dinamic (amicarbazone) - novo herbicida seletivo para o controle de plantas daninhas em pré e pós-emergência na cultura da cana-de-açúcar. In: CONGRESSO BRASILEIRO DA CIÊNCIA DAS PLANTAS DANINHAS, 24., 2004, São Pedro. Anais... São Pedro: Sociedade Brasileira da Ciência das Plantas Daninhas, 2004. p. 451

VELINI, E. D. et al. Avaliação da seletividade da mistura de oxyfluorfen e ametryne, aplicada em pré e pós emergência, a dez variedades de cana-de-açúcar (cana-planta).

Planta Daninha, v. 18, n. 1, p. 123-134, 2000.

YAMAMOTO, Y. Quality control of photosystem II. Plant Cell Physiol., v. 42, n. 2, p. 121-128, 2001

YORDANOVA, E. et al. Influence of the herbicide chlortoluron on photosynthetic activity in transgenic tobacco plants. Photosynthetica, v. 39, n. 2, p. 313-316, 2001 